\title{
Unusual Carbon Shielding Effects of Cyclopropanes and Double Bonds in Strained Bicyclo[3.1.0]hexanes and Cyclopentenes
}

Manfred Christ!* and Rainer Herbert

Institut für Organische Chemie der Universität Würzburg, Am Hubland, D-8700 Würzburg, Germany

\begin{abstract}
Carbon-13 shieldings and one-bond ${ }^{13} \mathrm{C}-\mathrm{H}$ coupling constants of bicyclo[2.1.1]hexane, bicyclo[2.1.1]hex2-ene, tricyclo[3.1.1. $0^{2,4}$ heptane and benzvalene are presented and compared to the data of related compounds. If a bicyclo[3.1.0]hexane system is part of a rigid skeleton, the cyclopropane ring exerts specific $\gamma$ substituent effects of two kinds. In the case of the bicyclohexane boat form an upfield shift of the C-3 signal is observed and in the case of the chair form a downfield shift of 15-20 ppm. Compared to the corresponding cyclopentanes the double bond in strained cyclopentenes causes downfield shifts of the C-4 absorption. This effect increases with increasing strain, reaching a $45.9 \mathrm{ppm}$ maximum in benzvalene. Hence it is the only known bicyclo[1.1.0]butane having a reversed order of carbon shieldings. The downfield shifts are explained by means of simple orbital interaction schemes.
\end{abstract}

The ${ }^{13} \mathrm{C}$ NMR spectra of the tricyclooctene isomers 1 and 2 reveal the remarkable anomaly that the shieldings of the two C-8 carbons differ by $26.3 \mathrm{ppm}^{1.2}$ (Fig. 1). (For ${ }^{13} \mathrm{C}$ NMR data of tricyclo[3.2.1.0 $\left.0^{2,4}\right]$ octane derivatives showing the same phenomenon see Ref. 2.) In tetracyclo[4.1.0.0 $0^{2.4} \cdot 0^{3.5}$ ]heptane (4) this phenomenon is observed intramolecularly, C-3 absorbing $26.1 \mathrm{ppm}$ downfield from the C-4 resonance. ${ }^{3} \mathrm{By}$ comparison with the hydrocarbons devoid of the cyclopropane ring, 3 and 5 respectively, these differences may be expressed as substituent effects as shown in Table 1.
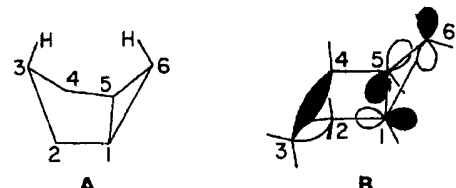

The upfield shifts can be viewed as normal $\gamma$ effects $^{4 a}$ (for the most recent critical study see Ref. 5) of the cyclopropane methylene group on $\mathrm{C}-3$ in a bicyclo[3.1.0]hexane boat form $\mathbf{A}$, which is fixed in $\mathbf{1}$ and 4. Downfield shifts are observed if the bicyclo[3.1.0]hexane moiety is present in the chair conformation as in 2 and also in 4 . Formula $B$ demonstrates that in this case the unoccupied cyclopropane Walsh orbital $\left(a_{2}{ }^{\prime}\right)$ and the highest occupied orbital of the C$2-\mathrm{C}-3$ and $\mathrm{C}-3-\mathrm{C}-4$ bonds mix, causing an electron deficiency at C-3 and hence a downfield shift of its NMR signal. These considerations, which are supported by charge density calculations, allow the determination of the conformation of bicyclo[3.1.0]hexane itself by means of the ${ }^{13} \mathrm{C}$ NMR spectrum. ${ }^{3}$

We have now synthesized tricyclo[3.1.1.0 $\left.0^{2.4}\right]$ heptane (7), whose carbon skeleton is closely related to that of 4. In 7 the shieldings of C-6 and C-7 show a difference

* Author to whom correspondence should be addressed.

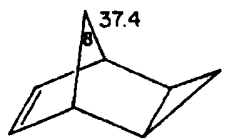

10

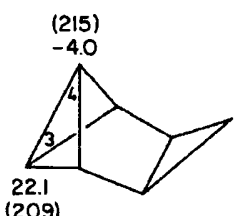

$4^{b}$

$$
\text { (140) }
$$$$
25
$$

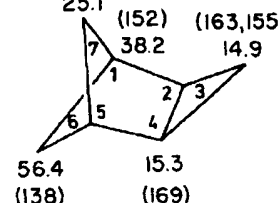

(138)

(169)

$7^{\mathrm{c}}$<smiles>CC(C)(C)C1C=CC2C=CC1C2</smiles>

$10^{\mathrm{e}}$

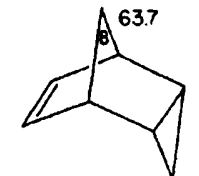

$2^{a}$

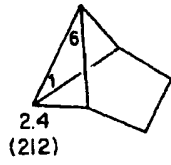

$5^{b}$

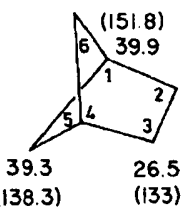

$8^{c, d}$

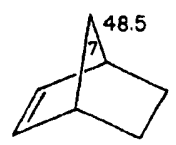

$3^{0}$

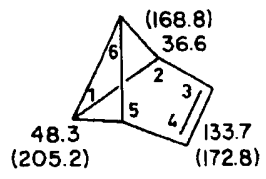

$6^{c}$
Figure 1. Carbon-13 shieldings (in ppm downfield from internal TMS) and one-bond ${ }^{13} \mathrm{C}-\mathrm{H}$ coupling constants (in $\mathrm{Hz}$, in parentheses) of some bicyclo[3.1.0]hexane, cyclopentene and cyclopentane derivatives.

- Ref. $1 . \quad$ Ref. 3.

c This work, solvent $\mathrm{CDCl}_{3}$.

a Slightly different data have been reported recently by $E . W$. Della, P. T. Hine and H. K. Patney, J. Org. Chem. 42, 2940 (1977).

- Ref. 4, p. $79 . \quad$ 'Ref. 4, p. 68.

Ref. 4, p. 84. ' Ref. 4, p. 60.

CCC-0030-4921/79/0012-0150\$01.50 
Table 1. Cyclopropane effects (in ppm) in bicyclo[3.1.0]hexanes, calculated by subtracting the shieldings of the appropriate carbons in the corresponding cyclopentanes

\begin{tabular}{ccrcc}
\hline Compound & $s y n$ & $\Delta \delta$ & anti & $\Delta 8$ \\
1 & $\mathrm{C}-8$ & -11.1 & & - \\
2 & & - & $\mathrm{C}-8$ & 15.2 \\
4 & $\mathrm{C}-4$ & -6.4 & $\mathrm{C}-3$ & 19.7 \\
7 & $\mathrm{C}-7$ & -14.2 & $\mathrm{C}-6$ & 17.1 \\
$\begin{array}{c}\text { Bicyclo[3.1.0]- } \\
\text { hexane }\end{array}$ & $\mathrm{C}-3$ & -6.3 & & - \\
\hline
\end{tabular}

of $31.3 \mathrm{ppm}$, which by comparison with bicyclo[2.1.1]hexane (8) can be split into 14.2 ppm upfield shift and a 17.1 ppm downfield shift of the C-7 and C-6 signals, respectively. As a consequence of the enhanced interaction depicted in $\mathbf{A}$, the upfield shift in $\mathbf{7}$ is much larger than in 4. The occupied $\sigma$ orbitals, involved in interaction $B$, are $a_{2}$ of bicyclo[1.1.0]butane ${ }^{6}$ in 4 and $b_{1 \mathrm{~g}}$ of cyclobutane ${ }^{6}$ in 7 . For steric reasons, only the half of each, which is arranged anti relative to the fused cyclopropane, mixes with the empty $a_{2}^{\prime}$ of cyclopropane. The much larger energy separation between $b_{1 \mathrm{~g}}$ and $a_{2}{ }^{\prime}$ compared to the $a_{2}-a_{2}{ }^{\prime}$ distance ${ }^{6}$ results in a weaker mixing and consequently in a less efficient charge transfer in 7. It therefore shows a smaller cyclopropane anti effect than 4 . As seen in Table 1, this trend is continued in 2 , because cyclopentene $\sigma$ electrons are still less prone to delocalization.

An acceptor orbital of proper symmetry analogous to $a_{2}{ }^{\prime}$ of cyclopropane is present in $\pi^{*}$ of the olefinic double bond. $\mathbf{C}$ and $\mathbf{D}$ show that now four CC bonds of cyclobutane and bicyclobutane, respectively, are involved in the interaction. This should be stronger compared to the cyclopropane case discussed above, because $\pi^{*}$ is much lower in energy than $a_{2}{ }^{\prime 6}$. Indeed the introduction of the double bond on going from 8 to 9 causes a downfield shift of the C-5,6 signal by $28.7 \mathrm{ppm}$ (Table 2). In benzvalene (6) the downfield shift of the C-1,6 signal is even larger $(45.9 \mathrm{ppm})$. The enhancement of the effect in going from 9 to 6 parallels the decreasing energy separation between donor and acceptor orbitals in these molecules.

The downfield shift of the C-7 signal in norbornene (3) compared to norbornane (11) (Table 2) can be explained in the same way, the decreased magnitude being a consequence of the stability of the relevant $\sigma$ orbital. In norbornadiene (10), however, the interaction of the two double bonds leads to a low-lying $\pi^{*}$ orbital. ${ }^{6}$ Formula $\mathbf{E}$ denotes the electron withdrawal

Table 2. Double bond effects (in ppm) in cyclopentenes, calculated by subtracting the shieldings of the corresponding cyclopentanes

\begin{tabular}{ccc}
\hline Compound & & $\Delta \delta$ \\
6 & $\mathrm{C}-1,6$ & 45.9 \\
9 & $\mathrm{C}-5,6$ & 28.7 \\
10 & $\mathrm{C}-7$ & 26.9 \\
3 & $\mathrm{C}-7$ & 9.8 \\
12 & $\mathrm{C}-4$ & -3.4 \\
\hline
\end{tabular}

- Relative to norbornene.

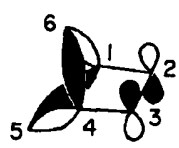

c

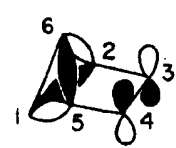

D

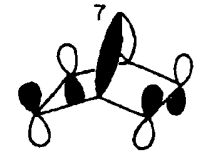

from C-7, which resonates at extremely low field $(75.4 \mathrm{ppm})$. For steric reasons the orbital interactions discussed are not possible in cyclopentene (12). Accordingly, no downfield shift of the C-4 signal is observed and this appears $3.4 \mathrm{ppm}$ upfield of the cyclopentane (13) resonance.

The large energy separations between donor and acceptor orbitals (at least 0.65 atomic units ${ }^{6}$ ) make their mixings and therefore the charge transfers comparatively small. As estimated from calculations carried out with 4 and 5,320 millielectrons at the most are withdrawn from the carbons concerned. That this is sufficient to account for the observed effects has recently been shown by Fliszár and coworkers. ${ }^{7}$ Obviously the influence of $\sigma$ electron density on carbon shielding is larger by a substantial magnitude compared to $\pi$ electron density, in which case the influence is about $160 \mathrm{ppm}$ per electron. ${ }^{4 \mathrm{~b}}$

The spectrum of benzvalene (6) deserves some further comment. As a consequence of the low-field resonance of $\mathrm{C}-1,6$ (parallel to the low-field absorption of $\mathrm{H}-1,6$ at $\delta 3.72 \mathrm{ppm}), 6$ is the only known bicyclo[1.1.0] butane having a reversed order of resonances. Usually the signals of bicyclobutane bridgehead carbons appear close to zero $\mathrm{ppm}^{3}{ }^{3}$ in sharp contrast to $\mathrm{C}-1,6$ of 6 . Nevertheless, the assignment is unambiguous on the basis of the one-bond ${ }^{13} \mathrm{C}-\mathrm{H}$ coupling constants (Fig. 1). Remarkably this $\mathrm{C}-1,6$ parameter is somewhat smaller than in $\mathbf{5}$. Similarly $C-3$ and $C-4$ in 4 have different coupling constants. Long range coupling in 6 results in a $4.4 \mathrm{~Hz}$ doublet for $\mathrm{C}-1,6\left[{ }^{3} \mathrm{~J}(\mathrm{C}-1, \mathrm{H}-6)\right]$, a $5.6 \mathrm{~Hz}$ quartet for $\mathrm{C}-3,4$ and a quartet $(12.2 \mathrm{~Hz})$ of triplets $(3.5 \mathrm{~Hz})$ for C-2,5.

It should be noted that the described effect of the double bond and the cyclopropane ring is completely lost if the symmetry is lowered by the introduction of one methylene group. Thus the relevant carbon shieldings in tricyclo[4.1.0.0 $\left.0^{2.7}\right]$ hept-3-ene (homobenzvalene $)^{3,8}$ and tetracyclo $\left[5 \cdot 1 \cdot 0.0^{2.4} \cdot 0^{3.5}\right]_{\text {octane }^{8}}$ deviate by less than $2.5 \mathrm{ppm}$ from the reference resonance in tricyclo $\left[4.1 .0 .0^{2,7}\right]$ heptane. ${ }^{3}$

\section{EXPERIMENTAL}

The synthesis of tricyclo[3.1.1.0 $\left.0^{2,4}\right]$ heptane $((7)$ was accomplished by the application of a procedure developed by Szeimies and coworkers ${ }^{9}$ to transform bicyclo[1.1.0]butanes to cyclobutanes. Thus we added thiophenol to $4^{10}$ and desulphurized the reaction product with lithium in ethylamine to obtain 7 in $71 \%$ overall yield. Details will be reported elsewhere.

Bicyclo[2.1.1] hexane (8) was prepared by WolffKishner reduction of bicyclo[2.1.1] hexan-2-one, which is easily accessible. ${ }^{11}$ Its tosylhydrazone is the starting material for the synthesis of bicyclo[2.1.1]hex-2-ene 


\section{CHRISTL AND R. HERBERT}

(9)..$^{12} \mathrm{~A}$ modified procedure ${ }^{13}$ proved to be the most useful for our purposes.

Benzvalene (6) in deuteriochloroform was obtained by a modification of the published procedure, ${ }^{14}$ which furnishes an ether solution of 6 . The second portion of methyllithium in ether was replaced by butyllithium in decalin. In the final distillation only benzvalene, accompanied by some benzene, methylene chloride and residual ether (from the first portion of methyllithium in ether), evaporated and this was condensed in a flask containing deuteriochloroform. Its quantity was arranged so as to provide a benzvalene concentration suitable for spectral accumulation. Because of the thermal instability of 6 , the measurements were carried out at $253 \mathrm{~K}$.

The pulse Fourier transform spectra were obtained on a Bruker WH-90 instrument at $22.64 \mathrm{MHz}$, using internal TMS as reference. The carbon shieldings are reproducible to $0.1 \mathrm{ppm}$, and in the coupling constants the last digit of each value given in Fig. 1 is uncertain.

\section{Ackmowledgement}

This work was supported by the Deutsche Forschungsgemeinschaft. R. H. is grateful to the Stiftung Stipendien-Fonds des Verbandes der Chemischen Industrie for a scholarship. M. C. is indebted to Professor R. W. Hoffmann, University of Marburg, for stimulating discussions.

Note added th proof: Because benzene rings also have a true $\pi^{*}$ orbital they cause downfield effects similar to those associated with double bonds. Accordingly, in 3,4-benzobenzvalene (naphthvalene) the $C-1,6$ signal appears at $42.4 \mathrm{ppm}$, corresponding to a $40.0 \mathrm{ppm}$ downfield shift relative to the $C-1,6$ signal in 5 .

\section{REFERENCES}

1. K. Tori, M. Ueyama, T. Tsuji, H. Matsumura and H. Tanida, Tetrahedron Lett. 327 (1974).

2. A. K. Cheng and J. B. Stothers, Org. Magn. Reson. 9, 355 (1977).

3. M. Christl, Chem. Ber. 108, 2781 (1975)

4. J. B. Stothers, Carbon-13 NMR Spectroscopy, Academic Press, New York (1972); (a) p. 57; (b) p. 91.

5. K. Seidman and G. E. Maciel, J. Am. Chem. Soc. 99, 659 (1977).

6. W. L. Jorgensen and L. Salem, The Organic Chemist's Book of Orbitals, Academic Press, New York, (1973).

7. S. Fliszár, A. Goursot and H. Dugas, J. Am. Chem. Soc. 96, 4358 (1974).

8. M. Christl and W. Buchner, Org. Magn. Reson. 11, in press.

9. G. Szeimies and A. Schlosser, Tetrahedron Lett. 3631 (1971); G. Szeimies, A. Schlosser, F. Philipp, P. Dietz and W. Mickler, Chem. Ber. 111, 1922 (1978).
10. M. Christl and G. Brüntrup, Angew. Chem. 86, 197 (1974); Angew. Chem. Int. Ed. Engl. 13, 208 (1974); M. Christl, G. Freitag and G. Brontrup, Chem. Ber. 111, 2307 (1978).

11. F. T. Bond, H. L. Jones and L. Scerbo, Organic Photochemical Syntheses, Vol. 1, p. 33. Wiley-Interscience, New York (1971).

12. J. Meinwald and F. Uno, J. Am. Chem. Soc. 90,800 (1968).

13. $H$. Musso and $W$. Trautmann, unpublished results; $W$. Trautmann, Dissertation, University of Karlsruhe 1976.

14. T. J. Katz, R. J. Roth, N. Acton and E. J. Carnahan, Org. Synth. 53, 157 (1973).

Received 10 March 1978; accepted 8 May 1978.

(C) Heyden \& Son Ltd, 1979 